\title{
Impact of Gender and Age on the Repertory of Coping to Tunisian Collective Sport
}

\author{
Jamel Hajji ${ }^{1,2 *}$, Adam Owen ${ }^{6}$, Foued ben Abdallah ${ }^{2}$, Anouer Bettaeib ${ }^{2}$, Maher Guerchi' ${ }^{2}$, Mohamed \\ Sami Zguira ${ }^{2}$, Nicola Bragazzi ${ }^{3,4}$ and Ali Elloumi ${ }^{5}$
}

${ }^{1}$ Faculty of Humanities and Social Sciences of Tunis, University of Tunis, Tunisia

${ }^{2}$ Higher Institute of Physical Education and Sports Gafsa, University of Gafsa, Tunisia

${ }^{3}$ Department of Health Sciences (DISSAL), Genoa, Italy

${ }^{4}$ Department of Experimental Medicine (DIMES), Genoa, Italy

${ }^{5}$ Department of Sociology, Faculty of Arts of Sfax, University of Sfax, Tunisia

${ }^{6}$ Inter-university Laboratory of Human Movement Biology (EA 7424), Claude Bernard Lyon 1, Lyon, France

*Corresponding author: Jamel Hajji, Faculty of Humanities and Social Sciences of Tunis, University of Tunis, Higher Institute of Physical Education and Sports Gafsa, University of Gafsa, Tunisia

\section{ARTICLE INFO}

Received: 幽 February 26, 2020

Published: March 09, 2020

Citation: Jamel H, Adam O, Foued ben A, Anouer B, Maher G, et al., Impact of Gender and Age on the Repertory of Coping to Tunisian Collective Sport. Biomed J Sci \& Tech Res 26(3)-2020. BJSTR. MS.ID.004354.

Keywords: Gender; Age; Coping; Collective Sport

\section{ABSTRACT}

The objective of this article is to present the results of a study on the impact of age and sex on the repertory of coping used by Tunisian athletes in collective sport. In this context, we used the Arabic version of the inventory of sports adaptation strategies (Hajji et al., 2016) for 419 athletes, including 278 men and 141 women with an average age of 19.00 years $(S D=5.52)$. This measuring instrument includes ten first-order coping strategies arranged into three second-order coping strategies. The processing of the data collected by the IBM SPSS software showed the following results. Our study showed that female teen athletes are more likely to adopt coping strategies aimed at disengagement. However, male teen athletes use a task and distraction repertoire of coping. On the other hand, adult female athletes are moving more towards the coping of disengagement and distraction. However, adult male athletes use more task-based coping. Age and gender are therefore variables that directly influence the repertoire of coping among Tunisian athletes in team sport.

\section{Introduction}

Understanding how the athlete adopts coping strategies in the context of collective sport is a major issue, not only in terms of preventing risks to well-being, but also in terms of optimizing performance. Performance in team sports is part of a social environment characterized by several personal interactions (between athletes, athletes and staff...). In this approach, athletes must not only learn, acquire and maintain a high level of athletic competence. However, it is also essential to develop a repertory of coping strategies to meet the demands of this specific environment Hardy, et al. [1] Managing the stressful situation and studying its aspects at the level of collective sport is a well-developed research area is a priority for several authors Crocker, et al. [2] Tamminen et al., 2014; Nicholls, et al. [3] Moreover, represents, the crucial objective of our work to understand how Tunisian athletes manifest themselves in a competitive, stressful environment and what are the strategies of the coping shared with the performance in the context of collective sport characterized by the complexity of social relations.

Several approaches are based on the bipolarity of stress and coping in the field of sport does not directly meet our demands. Such as the cognitive-motivational-relational theory (TCMR) of emotions Lazarus, et al. [4,5] which forms a theoretical model frequently used in studies centralizing stress and coping, and is fundamentally based on cognitive assessment.In accordance with the "transactional" model of Lazarus and Folkman, coping is a dynamic mechanism that changes according to the situation. 
Coping is one of the most centralized research concepts in sport Doron, et al. [6,7] Coping is a good predictor of performance Amiot, et al. [8-12] Thanks to this concept, the explanatory mechanism of the stressful event and its consequences can be better understood Beal, et al. [13]. To manage the specific stressful demands of the competition and to optimize performance, the athlete adapts to this mechanism Calmeiro, et al. [14-17] and seeks to overcome the stressful situation in order to maximize its chances of success Molinero, et al. [18].

However, can this transactional model, which concentrates the dynamic mechanism of coping, share the same concepts in collective and individual sport? In fact, Gaudrea, et al. [19] see coping as an adjustment of stress at the collective level rather than at the individual level. This approach has recently been formalized for collective competitive situations. On the other hand, the coping repertory used by the athlete affected by an individual or collective environment is also subject to more influential and more exhaustive factors such as age and gender. The age transition involves a radical shift in bio-psycho-social stability Baker, et al. [20] The high-level athlete integrates with these changes and faces at the same time an intense sports investment. Stress management must be consistent with age transition, and the athlete must be progressive and effective in this transformation Nicholls, et al. [21]. According to Tamminen, et al. [22] coping is an ability that can develop based on experience and age transition. Hanton, et al. [23] indicate that experience also influences coping strategies. For them, the high level of experience among elite athletes is more oriented to problem-based strategies.

The athlete's level of experience can therefore influence the choice and use of coping despite the overlap of personal relationships such as pairs, parents, coaches..... On the other hand, the athlete's gender also plays an important role in the coping's orientation in the face of the threatening competitive situation. For Hoar, et al. [24] the gender-related qualities of coping remain poorly conceived. This flaw makes it difficult for the coach and mental trainer and even the athlete to respond and improve their performance. In general, the majority of studies in this field show that women often turn to emotional coping strategies, while men frequently turn to problem-oriented coping.Crocker, et al. [25] explain this spontaneous tendency of women towards emotional coping and men towards problem coping, through stereotypical roles and expectations of gender roles. Adaptation strategies therefore take on different aspects depending on the characteristics of the person and his reactions with his environment.Recently, Nicholls, et al. $[26,27]$ proposed a three-dimensional classification of adaptation that focuses on control, internal regulation and disengagement. Previously, research centralizing sports competition, and conducted with 144 golfers during the 2002 Quebec Junior and Amateur Championships, indicated that these golfers used 90 actions to manage their stress in the face of competition.

These adjustments were then grouped into ten adaptation strategies and arranged into three main chapters: task-based adaptation strategies, distracted adaptation strategies and disengagement-based adaptation strategies Gaudreau, et al. $[28,29]$. Task-oriented coping strategies are designed to deal directly with the source of stress. This dimension merges the adaptation centered on the problem (exertion, logical analysis...) and the adaptation centered on the emotion (relaxation, control of the thought). In contrast, avoidance strategies include exitoriented strategies that are used to escape the threatening situation. In addition, distraction-oriented strategies, which are used to temporarily de-center any provocations from the stressful situation. The current study centralizing variation in coping styles in the face of competitive stress among Tunisian athletes is trying to broaden our understanding of the difference in coping styles between gender and age. The use of a random sample of athletes affiliated with popular collective sports in Tunisia makes it possible to generalize to all adolescent and adult athletes, male and female. The review of the coping repertory among our participants adds valuable information on the skill level to manage competitive stress and anxiety and on preventive strategies to intervene in different phases of age and in relation to the athlete's gender.

\section{Methodology}

\section{Population}

419 athletes from collective sports including 278 men and 141 women with an average age of 19.00 years (SD: 5.52 years). At the national and international level, voluntarily participated in this study see Table 1.

Table 1: Demographic characteristics of participants.

\begin{tabular}{|c|c|c|}
\hline & Numbers & Percentage \\
\hline Adult man & 100 & 23.9 \\
\hline Adult woman & 56 & 13.4 \\
\hline Total adult & 156 & 37.2 \\
\hline Adolescent man & 178 & 42.5 \\
\hline Adolescent woman & 85 & 20.3 \\
\hline Total adolescent & 263 & 62.8 \\
\hline Total & 419 & 100 \\
\hline
\end{tabular}

\section{Measures}

In this study, we used the Arabic version of the inventory of sports competition adaptation strategies (Hajji Jamel et al., 2016). This questionnaire consists of 39 elements divided into ten firstorder coping strategies, and three second-order coping strategies: task-based coping strategies, exit-oriented adaptation strategies and distraction-oriented adaptation strategies.

\section{Procedures}

Participants were asked to answer a 5-point Likert scale, ranging from 1 (never) to 5 (always), two hours after the competition. This questionnaire is designed to identify first and second-order coping strategies used to manage pre-competitive anxiety. All participants were previously informed about the purpose and procedure of the 
study. Participation was voluntary and following the ethical charter, parental consent was required for athletes under 18 years of age.

\section{Results}

\section{Effect of Sex and Age on Coping}

The Levene homogeneity test indicates that the variance of the scores of different coping strategies is homogeneous ( $p$-value $>5 \%$ ). This allows us to perform the MANOVA multiple variance analysis to examine the effect of age and sex on the coping repertoire of our participants see (Tables $2 \& 3$ ) shows the correlations between the 10 coping strategies used by our participants. As shown in (Table 3), correlations between variables did not exceed 0.51 , suggesting that multiple collinearity would not be a concern in variation analyses. The multiple variance analysis (MANOVA) indicates that sex and age have significant effects (Wilks lambda is significant at $\mathrm{P}<5 \%$ ) on the choice of coping among Tunisian athletes in the collective sport see (Tables 4 \& 5).

Table 2: Demographic characteristics of participants.

\begin{tabular}{|c|c|c|c|c|}
\hline & Statistics Levene & ddl1 & ddl2 & p-value \\
\hline Mental imagery & ,642 & 6 & 262 & ,696 \\
\hline Effort expenditure & 1,825 & 6 & 262 & ,095 \\
\hline Thought control & ,149 & 6 & 262 & ,989 \\
\hline Seeking support & ,378 & 6 & 262 & ,893 \\
\hline Relaxation & ,345 & 6 & 262 & ,912 \\
\hline Logical analysis & ,623 & 6 & 262 & ,712 \\
\hline $\begin{array}{l}\text { Venting of unpleasant } \\
\text { emotions }\end{array}$ & 1,894 & 6 & 262 & ,082 \\
\hline Disengagement & 2,829 & 6 & 262 & 011 \\
\hline Social withdrawal & 1,394 & 6 & 262 & ,217 \\
\hline Mental distraction & 5,300 & 1 & 292 & ,022 \\
\hline
\end{tabular}

Table 3: Inter-correlations among age and gender and coping repertory $(\mathrm{N}=419)$.

\begin{tabular}{|c|c|c|c|c|c|c|c|c|c|}
\hline & 1 & 2 & 3 & 4 & 5 & 6 & 7 & 8 & 9 \\
\hline Mental imagery & 1 & & & & & & & & \\
\hline Effort expenditure &, $395^{* *}$ & 1 & & & & & & & \\
\hline Thought control &, $370^{* *}$ &, $439 * *$ & 1 & & & & & & \\
\hline Seeking support &,- 072 &,- 027 & 062 & 1 & & & & & \\
\hline Relaxation &, $309 * *$ &, $146^{* *}$ &, $247^{* *}$ &,- 059 & 1 & & & & \\
\hline Logical analysis &, $489 * *$ &, $473^{* *}$ &, $375^{* *}$ & 014 &, $381^{* *}$ & 1 & & & \\
\hline Venting of emotions &, 032 &, $188^{* *}$ &, $218^{* *}$ & ,103* &,- 021 & ,103* & 1 & & \\
\hline Disengagement &, $387^{* *}$ &, $316^{* *}$ &, $348^{* *}$ &,- 041 & ,209** &, $312^{* *}$ &, $506^{* *}$ & 1 & \\
\hline Social withdrawal &, $138 * *$ &,- 011 &,- 045 &,- 089 &, $227^{* *}$ & ,030 &,$- 286^{* *}$ &,- 050 & 1 \\
\hline Mental distraction &,$- 146^{* *}$ &,$- 119 *$ &,$- 217^{* *}$ &,- 090 &,$- 121^{*}$ &,$- 341^{* *}$ &,$- 242^{* *}$ &,$- 226^{* *}$ &, $221^{* *}$ \\
\hline
\end{tabular}

Note: ${ }^{* *} \mathrm{p}<.01 .{ }^{* * *} \mathrm{p}<.001$.

Table 4: Effect of sex on coping.

\begin{tabular}{|c|c|c|c|c|c|c|}
\hline Effect & Value & D & ddl of the hypothesis & Ddl error & Sig. & \\
\hline Sexe & Trace of Pillai &, 178 & $6,129 \mathrm{~b}$ & 10,000 & 283,000 &, 000 \\
\hline & Wilks Lambda &, 822 & $6,129 \mathrm{~b}$ & 10,000 & 283,000 &, 000 \\
\hline & Hotelling Trace &, 217 & $6,129 \mathrm{~b}$ & 10,000 & 283,000 &, 000 \\
\hline & Largest Roy Root &, 217 & $6,129 \mathrm{~b}$ & 10,000 & 283,000 &, 000 \\
\hline
\end{tabular}

Note:

a. Plan: Originally ordered + Sex

b. Exact statistics 
Table 5: The effect of age on coping.

\begin{tabular}{|c|c|c|c|c|c|c|}
\hline Effect & Value & D & $\begin{array}{l}\text { ddl of the } \\
\text { Hypothesis }\end{array}$ & Ddl Error & Sig. & \\
\hline \multirow[t]{4}{*}{ AGE } & Trace of Pillai & ,692 & 1,207 & 170,000 & 2760,000 & ,039 \\
\hline & Wilks Lambda & ,471 & 1,247 & 170,000 & 2336,235 & 020 \\
\hline & Hotelling Trace & ,824 & 1,286 & 170,000 & 2652,000 & 009 \\
\hline & Largest Roy Root & ,291 & $4,727 c$ & 17,000 & 276,000 &, 000 \\
\hline \multicolumn{7}{|c|}{ Plan: Originally ordered + AGE } \\
\hline \multicolumn{7}{|c|}{ The statistic is an upper bound of F that produces a lower bound for the significance threshold. } \\
\hline
\end{tabular}

\section{The Level of Coping According to the Age-Sex Crossing}

The Level of First-Order Coping in Male and Female Adolescents: Male adolescent athletes use more of the following coping strategies:

- $\quad$ The effort expenditure

- $\quad$ The mental imagery

- $\quad$ The thought control

In contrast, female adolescent athletes use the following coping strategies:
- $\quad$ The effort expenditure

- $\quad$ The thought control

- $\quad$ The venting of unpleasant emotions

- $\quad$ Logical analysis

- $\quad$ The mental imagery

However, adolescent male and female athletes use the mental distraction strategy in a similar way see (Table 6 \& Figure 1).

\section{ADOLESCENT Male $\longrightarrow$ ADOLESCENT Female}

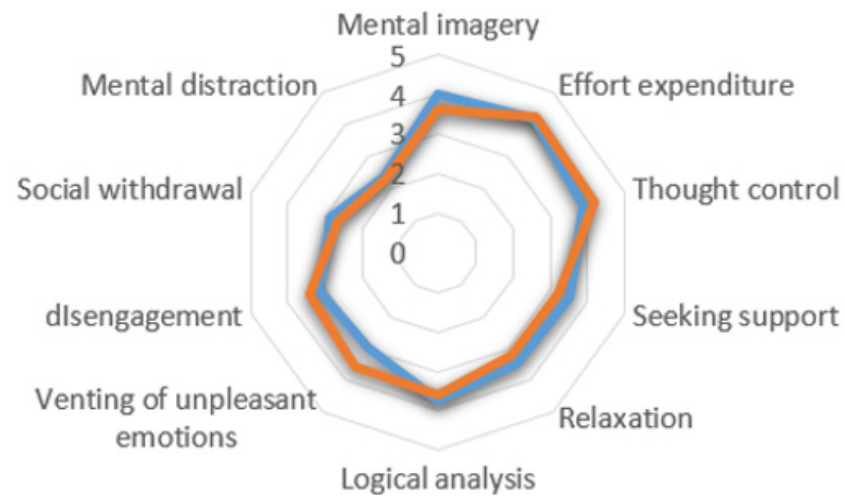

Figure 1: The level of first order coping among male and female adolescents.

Table 6: The level of first order coping in male and female adolescents.

\begin{tabular}{|c|c|c|c|c|c|c|c|c|c|c|c|}
\hline \multicolumn{2}{|c|}{ Adolescent } & \multirow{2}{*}{$\begin{array}{c}\begin{array}{c}\text { Mental } \\
\text { Imagery }\end{array} \\
3,99\end{array}$} & \multirow{2}{*}{$\begin{array}{c}\begin{array}{c}\text { Effort } \\
\text { Expenditure }\end{array} \\
4,19 \\
\end{array}$} & \multirow{2}{*}{$\begin{array}{c}\text { Thought } \\
\text { Control }\end{array}$} & \multirow{2}{*}{$\begin{array}{c}\text { Seeking } \\
\text { Support }\end{array}$} & \multirow{2}{*}{$\begin{array}{c}\text { Relaxation } \\
3,44\end{array}$} & \multirow{2}{*}{$\begin{array}{c}\text { Logical } \\
\text { Analysis }\end{array}$} & \multirow{2}{*}{$\begin{array}{c}\begin{array}{c}\text { Venting } \\
\text { of } \\
\text { Emotion }\end{array} \\
2,99\end{array}$} & \multirow{2}{*}{$\begin{array}{c}\begin{array}{c}\text { Disenga } \\
\text { gement }\end{array} \\
3,14 \\
\end{array}$} & \multirow{2}{*}{$\begin{array}{c}\text { Social } \\
\text { Withdrawal } \\
2,89 \\
\end{array}$} & \multirow{2}{*}{$\begin{array}{c}\text { Mental } \\
\text { Distraction } \\
2,33 \\
\end{array}$} \\
\hline \multirow{3}{*}{ Male } & Mean & & & & & & & & & & \\
\hline & SD & ,79 & ,87 & ,77 & 87 & ,82 & 90 & 1,06 & 1,20 & ,95 & 1,07 \\
\hline & $\mathrm{N}$ & 178 & 178 & 178 & 178 & 178 & 178 & 178 & 178 & 178 & 178 \\
\hline \multirow{3}{*}{ Female } & Mean & 3,62 & 4,25 & 4,15 & 3,23 & 3,21 & 3,60 & 3,60 & 3,42 & 2,65 & 2,30 \\
\hline & SD & ,79 & ,82 & ,82 & ,92 & 88 & ,84 & ,94 & 1,06 & ,96 & 91 \\
\hline & $\mathrm{N}$ & 85 & 85 & 85 & 85 & 85 & 85 & 85 & 85 & 85 & 85 \\
\hline
\end{tabular}


The Level of First-Order Coping in Adult Males and Females: Adult male athletes are more likely to choose the following strategies:

- $\quad$ The effort expenditure

- $\quad$ The thought control

- $\quad$ The mental imagery

- $\quad$ The disengagement
- $\quad$ The logical analysis

In contrast, adult female athletes are more likely to seek the following strategies:

- $\quad$ The effort expenditure

- $\quad$ The thought control

In addition, adult male and female athletes use the following strategies in the same way see (Table 7 \& Figure 2):

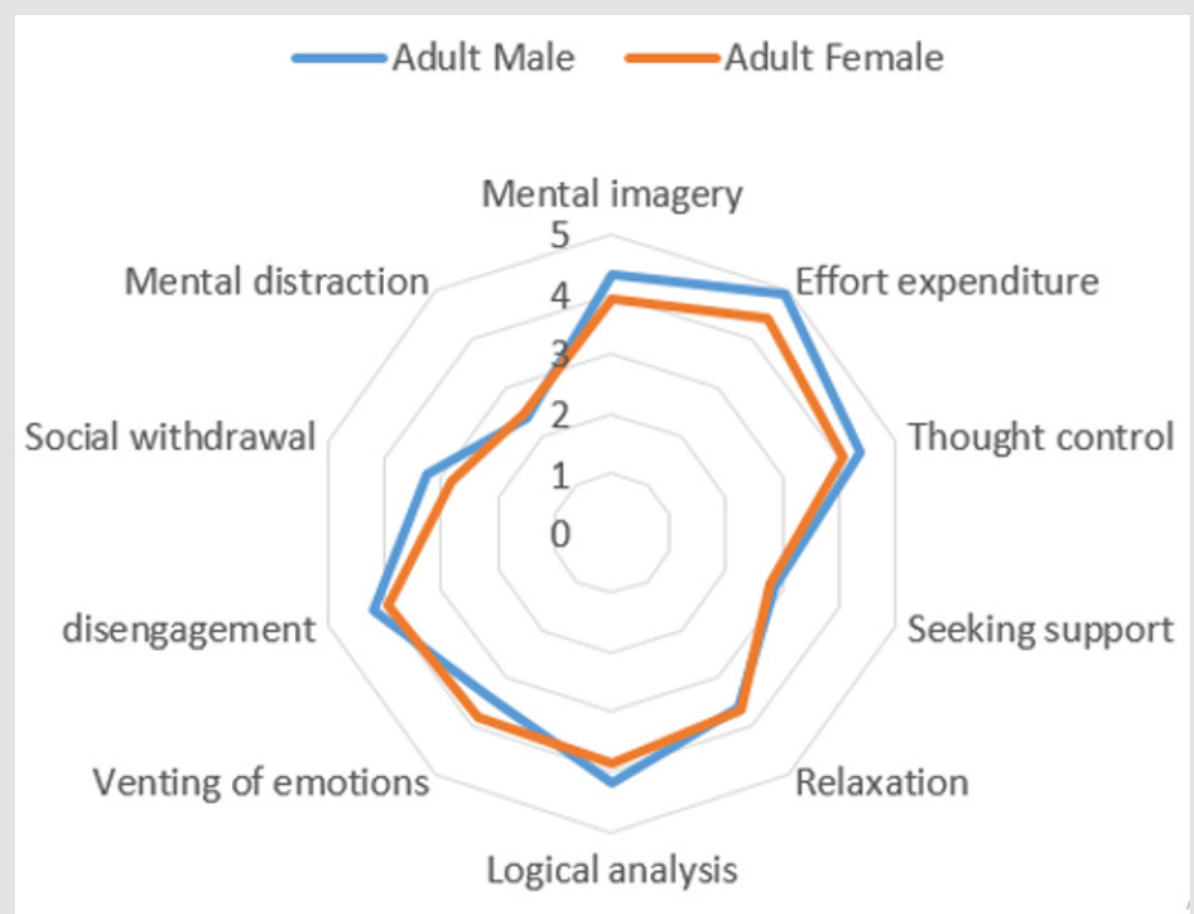

Figure 2: The level of first order coping among adult males and females.

Table 7: The level of first order coping in adult males and females.

\begin{tabular}{|c|c|c|c|c|c|c|c|c|c|c|c|}
\hline \multicolumn{2}{|c|}{ Adolescent } & Mental & $\begin{array}{c}\text { Effort } \\
\text { Expenditure }\end{array}$ & Thought & Seeking & Relaxation & $\begin{array}{l}\text { Logical } \\
\text { Analysis }\end{array}$ & $\begin{array}{c}\text { Venting } \\
\text { of }\end{array}$ & Diseng & $\begin{array}{c}\text { Social } \\
\text { Withdrawal }\end{array}$ & $\begin{array}{c}\text { Mental } \\
\text { Distraction }\end{array}$ \\
\hline \multirow{3}{*}{ Male } & Mean & 4,34 & 4,95 & 4,35 & 2,87 & 3,61 & 4,19 & 3,43 & 4,21 & 3,25 & 2,39 \\
\hline & SD & ,69 & ,11 & ,29 & ,86 & ,73 & ,39 & ,80 & ,64 & ,79 & ,88 \\
\hline & $\mathrm{N}$ & 100 & 100 & 100 & 100 & 100 & 100 & 100 & 100 & 100 & 100 \\
\hline \multirow{3}{*}{ Female } & Mean & 3,90 & 4,43 & 4,07 & 2,79 & 3,65 & 3,85 & 3,83 & 3,93 & 2,83 & 2,46 \\
\hline & SD & ,69 & ,69 & ,52 & ,85 & ,56 & ,78 & ,57 & ,63 & 1,06 & 81 \\
\hline & $\mathrm{N}$ & 56 & 56 & 56 & 56 & 56 & 56 & 56 & 56 & 56 & 56 \\
\hline
\end{tabular}

- The relaxation

- The mental distraction

The Level of Second-Order Coping in Male and Female Adolescents: For second-order coping, male adolescent athletes use more task-oriented and distraction coping strategies, whereas female adolescent athletes use more coping strategies oriented towards disengagement see (Table 8 \& Figure 3).

The Level of Second Order Coping in Adult Males and Females: Adult male athletes are using more task-based and distracted coping strategies. While adult male and female athletes are similarly engaging in exit-oriented coping strategies (Table 9 \& Figure 4). 


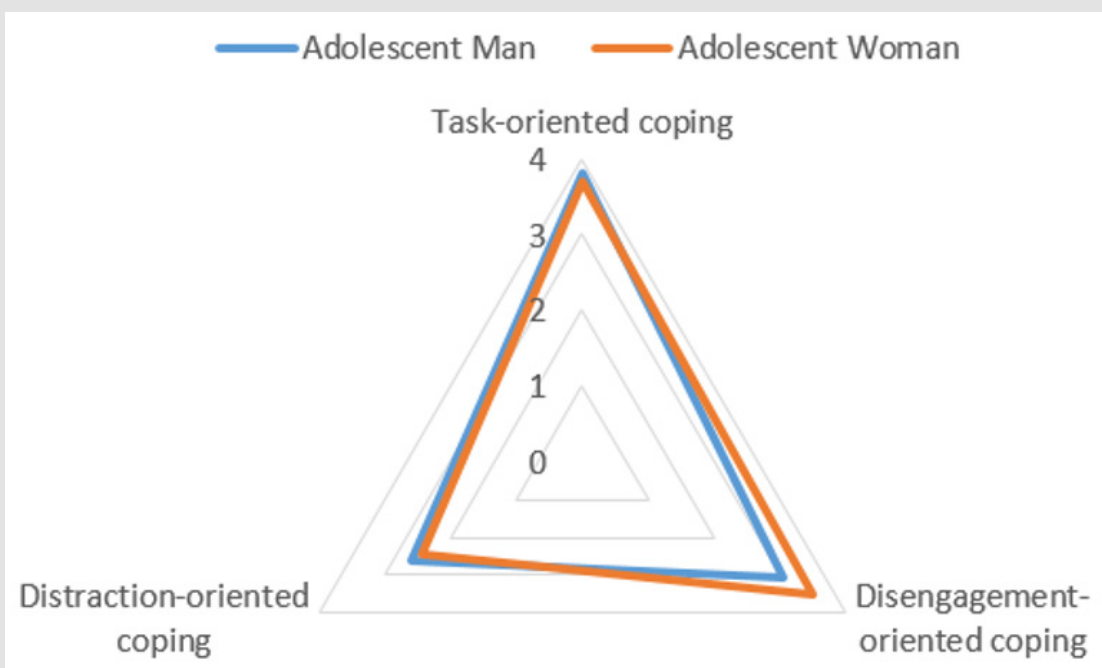

Figure 3: The level of second order coping in adolescent males and female athletes.

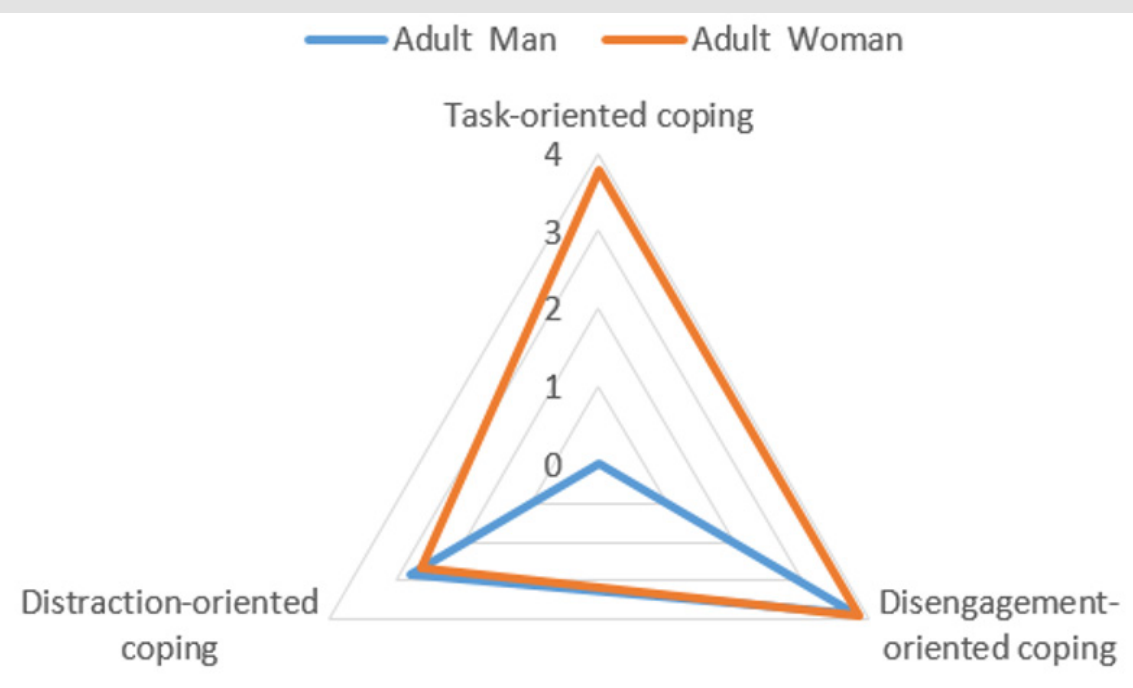

Figure 4: Second order coping in adult male and female athletes.

Table 8: The level of second order coping in adolescent males and female athletes.

\begin{tabular}{|c|c|c|c|c|c|c|}
\hline \multirow{2}{*}{ Second Order Coping } & \multicolumn{4}{|c|}{ Adolescent } \\
\cline { 2 - 7 } & \multicolumn{3}{|c|}{ Man } & Mean & SD & N \\
\cline { 2 - 7 } & Mean & SD & 178 & 3,68 &, 52 &, 85 \\
\hline Task-oriented coping & 3,80 &, 54 & 178 & 3,50 &, 65 \\
\hline Disengagement-oriented coping & 3,06 & 1,04 & 178 & 2,46 &, 65 & 85 \\
\hline Distraction-oriented coping & 2,61 &, 82 & &
\end{tabular}

Table 9: The level of second order coping in adult male and female athletes.

\begin{tabular}{|c|c|c|c|c|c|c|}
\hline \multirow{3}{*}{ Second Order Coping } & \multicolumn{6}{|c|}{ Adult } \\
\hline & \multicolumn{3}{|c|}{ Man } & \multicolumn{3}{|c|}{ Woman } \\
\hline & Mean & SD & $\mathbf{N}$ & Mean & SD & $\mathbf{N}$ \\
\hline Task-oriented coping & 4.05 & ,20 & 100 & 3,78 & ,36 & 56 \\
\hline Disengagement-oriented coping & 3,82 & 46 & 100 & 3,88 & 48 & 56 \\
\hline Distraction-oriented coping & 2,81 & 60 & 100 & 2,65 & 80 & 56 \\
\hline
\end{tabular}




\section{Discussion}

\section{The Effect of Age and Sex}

The MANOVA multiple variance analysis indicates that age has a significant effect on the coping repertory used by Tunisian athletes in a sport team. Our results are corroborated by some studies. The perception of the stressful situation during adolescence is not necessarily the same in adulthood. This may be related to the development of the level of experience and the evolution of the coping repertoire Compas, et al. [30].

The framework of temporal dynamics Kuppens, et al. [31] explains the relationship between age and coping strategies Carstensen, et al. [32-34,22] support the concept that adaptation is a capacity that can evolve with experience and age. On the other hand, the MANOVA multiple variance analysis conducted as part of this study confirms the influence of gender on the coping repertory among our participants. Our findings are corroborated by several studies, Callahan, et al. [35] indicate that numerous studies on coping demonstrate the influence of sex on the choice of adaptation used to overcome the threatening situation.

\section{The Level of Coping with Age and Sex}

Our work confirms that female adolescent athletes are using more exit-oriented coping strategies, such as Venting of unpleasant emotions and disengagement. On the other hand, male teen athletes are more oriented towards coping task, such as mental imaging strategies, seeking support, relaxation, logical analysis and social withdrawal. On the other hand, adult female athletes are moving more towards coping focused on disengagement and distraction, such as strategies of evacuating unpleasant emotions and mental distraction. However, male adult athletes are more task-oriented coping, such as effort spending strategies, thought control, logical analysis and mental imaging. The results revealed by our study are consistent with most studies in the field of sport. Compas, et al. [30] and Mccormick et al., (2007) found that adolescent athletes can better adapt to stressful events. Reeves et al., (2009), confirm that the average adolescent athlete benefits more from emotion, but that the early adolescent athlete is more concerned about problembased strategies. De Boo et al. (2009) show that older children are moving more towards cognitive strategies. Kowalski et al., (2001), reported that adolescents sometimes opt for avoidance-based adaptation through behavioural and cognitive leakage (Anshel et al., 2001). On the other hand, Chabrol, et al. [35] point out that young people are more focused on emotional strategies. The increasing age makes it easier to use problem-oriented strategies.

Adult athletes manage stress and better control their emotional reactions (Bebetsos et al., 2003). However, women generally seek social support to cope with stressful situations in sport Compas, et al. [30,25] Kolt et al., 1995; Philippe et al., 2004). In general, some studies show that men and women use different coping strategies (Anshel et al., 2001; Crocker, et al. [25] Yoo, 2001). However, other research finds no difference between the two sexes (Kowalski et al. 2005; Pensgaard et al., 1998; 1999), such as the study by Anshel et al., (2001) which indicate that no difference was found in soliciting social support and magical thinking among men and women.

\section{Conclusion}

This study, which examines the repertory of contextual coping used by Tunisian athletes to collective sport, confirms that age and gender have an influence on adaptation strategies. In addition, our participants use coping strategies randomly and not selectively, which may be consistent with the failure of mental preparation and competitive stress management. Task and distractionoriented coping strategies dominate the coping repertory of adolescent Tunisian male athletes. In contrast, adolescent Tunisian female athletes are more likely to use coping strategies geared towards disengagement. On the other hand, task-oriented and disengagement coping strategies dominate the repertoire of coping among Tunisian adult male athletes. However, female Tunisian adult athletes are more demanding coping strategies oriented towards distraction and disengagement. In the high-level, taskoriented coping strategies are always positively associated with performance Gaudreau, et al. [9,36,37,16,17] and even to selection in a professional level Van Yperen, et al. [38] On the other hand, strategies oriented towards disengagement and distraction are negatively associated with performance Friedel, et al. [39-42] Therefore, this study seems useful to understand how the coping process unfolds through age and gender. Moreover, how it manifests itself through the different situations encountered in the context of the collective sport in male and female Tunisian athletes.

\section{Limits}

One of the limitations of this study, on which we focused only on contextual adaptation, and we neglected the dispositional or intraindividual that is directly associated with personality traits and is characterized by its stability. Studies in the sports context have determined the effect of stable personality traits on coping choice Giacobbi, et al. [43-49].

\section{References}

1. Hardy L, Jones G, Gould D (1996) Understanding psychological preparation for sport: Theory and practice of elite performers. Chichester, UK.

2. Crocker PRE, Tamminen KA, Gaudreau P (2015) Coping in sport. In: SD Mellalieu, S Hanton (Eds.)., Contemporary advances in sport psychology. A review, Routledge, New York. p. 28- 67.

3. Nicholls A, Polman RCJ (2007a) Coping in sport: A systematic review. Journal of Sports Sciences 25(1): 11-31.

4. Lazarus RS (1999) Hope: An emotion and a vital coping resource against despair. Social Research 66 (2): 653-678.

5. Lazarus RS (2000) How emotions influence performance in competitive sports. The Sport Psychologist 14(3): 229-252.

6. Doron J, Stephan Y Le, Scanff C (2013) Les stratégies de coping : une revue de la littérature dans les domaines du sport et de l'éducation. Revue européenne de psychologie appliquée 63(5): 303-313. 
7. Hoar SD Kowalski KC, Gaudreau P, Crocker P (2006) A review of coping in sport. In: Hanton S, Mellalieu SD (Eds.)., Literature Reviews in Sport Psychology. Nova Science Publishers, New York NY. p. 47-90.

8. Amiot CE, Gaudreau P, Blanchard CM (2004) Self-determination, coping, and goal attainment in sport. Journal of Sport and Exercise Psychology 26(3): 396-411.

9. Gaudreau P, Antl S (2008) Athletes' broad dimensions of dispositional perfectionism: examining changes in life satisfaction and the mediating role of sport-related motivation and coping. Journal of Sport \& Exercise Psychology 30: 356-382.

10. Gaudreau P, Blondin JP (2004b) Differential associations of dispositional optimism and pessimism with coping, goal attainment, and emotional adjustment during sport competition. International Journal of Stress Management 11: 245-269.

11. Nicholls AR, Ntoumanis N (2010) Traditional and New Methods of Assessing Coping in Sport. In: Coping in Sport, Theory, Methods and Related Contructs. Nova Science Publishers. p. 35-51.

12. Nicholls AR, Levy AR, Polman RCJ (2012) A path analysis of stress appraisals, emotions, coping, and performance satisfaction among athletes. Psychology of Sport and Exercise 13(3): 263-270.

13. Beal DJ,Weiss HM, Barros E, MacDermid SM (2005) An Episodic Process Model of Affective Influences on Performance. Journal of Applied Psychology 90(6): 1054-1068.

14. Calmeiro L, Tenenbaum G, Eccles DW (2010) Event Sequence Analysis of Appraisals and Coping during Trapshooting Performance. Journal of Applied Sport Psychology 22: 392-407.

15. Calmeiro L, Tenenbaum G, Eccle DW (2014) Managing Pressure: Patterns of Appraisals and Coping Strategies of Non-Elite and Elite Athletes during Competition. Journal of Sports Sciences 32(19): 18131820.

16. Doron J, Gaudreau P (2014) A Point by Point Analysis of Performance in a Fencing Match : Psychological Processes Associated with Winning and Losing Streaks Journal of Sport and Exercise Psychology 36: 3-13.

17. Doron J, Martinent G (2016) Trajectories of Psychological States of Women Elite Fencers during the Final Stages of International Matches. Journal of Sports Sciences: 34(9): 836-842.

18. Molinero 0, Salguero, Alfonso, Márquez, Sara, et al. (2010) Psychometric properties and dimensional structure of the Spanish adaptation of the Coping Inventory for Competitive Sport. Psicothema 22(4): 975-982.

19. Gaudreau P, Miranda D (2010) Coping across time, situations, and contexts: A conceptual and methodological overview of stability, consistency, and change. In: AR Nicholls (Edt.)., Coping in sport: Concepts, theories, and related constructs. Nova, New York, p. 15-32.

20. Baker J, Horton S, Robertson Wilson J, Wall M (2003) Nurturing sport expertise: Factors influencing the development of elite athlete. Journal of Sports Science and Medicine 2(1): 1-9.

21. Nicholls AR, Polman R, Levy AR, Taylor J , Cobley S, et al. (2007) Stressors, coping, and coping effectiveness: Gender, type of sport, and skill differences. Journal of Sport Sciences 25(13): 1521-1530.

22. Tamminen KA, Holt NL (2010) Future-oriented approaches to coping. In: AR Nicholls (Edt.)., Coping in sport: Concepts, theories, and related constructs. Nova, New York, pp. 293-305.

23. Hanton S, Neil R, Mellalieu SD, Fletcher D (2008) Competitive experience and performance status: An investigation into multidimensional anxiety and coping. European Journal of Sport Science 8: 143-152.

24. Hoar SD, Crocker PRE, Holt NL, Tamminen KA (2010) Gender differences in adolescent athletes' coping with interpersonal stressors in sport: More similarities than differences? Journal of Applied Sport Psychology 22(2): 134-149.
25. Crocker PRE, Graham TR (1995) Coping by competitive athletes with performance stress: gender differences and relationships with affect. The Sport Psychologist 9(3): 325-338.

26. Nicholls AR, Morley D, Perry JL (2016) The model of motivational dynamics in sport: resistance to peer influence, behavioral engagement and disaffection, dispositional coping, and resilience. Front Psychol.

27. Nicholls AR, Levy A, Jones L, Meir, Radcliffe JN, et al. (2016) Committed relationships and enhanced threat levels: Perceptions of coach behavior, the coach-athlete relationship, stress appraisals, and coping among athletes. International Journal of Sports Science \& Coaching 11(1): 1626.

28. Gaudreau P, Blondin JP, Lapierre, Anne Marie (2002) Athletes' are coping during a competition: Relationship of coping strategies with positive effect, negative effect, and performance-goal discrepancy. Psychology of Sport and Exercise 3: 125-150.

29. Gaudreau P, El Ali, M Marivai T (2005) Factor structure of the Coping Inventory for Competitive Sport with a sample of participants at the 2001 New York marathon. Psychology of Sport and Exercise 6: 271-288.

30. Compas BE, ConnorSmith JK, SaltzmanH, Thomsen AH, Wadsworth ME, et al. (2001) Coping with stress during childhood and adolescence: Problems, progress, and potential in theory and research. Psychological Bulletin 127(1): 87-127.

31. Kuppens P (2010) From appraisal to emotion. Emotion Review 2: 157158.

32. Carstensen LL, Gross JJ, Fung H (1998) The social context of emotional experience. In: KW Schaie, MPLawton (Eds.)., Annual review of gerontology and geriatrics 17: 325-352.

33. Urry HL, Gross JJ (2010) Emotion regulation in older age. Current Directions in Psychological Science 19: 352-357.

34. Blanchard Fields F (2007) Everyday problem solving and emotion: An adult developmental perspective. Current Directions in Psychological Science 16: 26-31.

35. Callahan S, Chabrol H (2013) Mechanisms of Defense and Coping ( $2^{\text {nd }}$ Edn.)., Paris, Dunod.

36. Hill AP, Hall HK, Appleton PR (2010) Perfectionism and athlete burnout in junior elite athletes: The mediating influence of coping tendencies. Anxiety, Stress, \& Coping 23(4): 415-430.

37. Mouratidis A, Michou A (2011) Perfectionism, self-determined motivation, and coping among adolescent athletes. Psychology of Sport and Exercise 12: 355-367.

38. Van Yperen, NW (2009) Why some make it and others do not: Identifying psy- chological factors that predict career success in professional adult soccer. The Sport Psychologist 23: 317-329.

39. Friedel JM, Cortina KS, Turner JC, Midgley C (2007) Achievement goals, efficacy beliefs and coping strategies in mathematics: The roles of perceived parent and teacher goal emphases. Contemporary Educational Psychology 32: 434-458.

40. Kristiansen E, Roberts GC, Abrahamsen FE (2008) Achievement involvement and stress coping in elite wrestling. Scandinavian Journal of Medicine \& Science in Sports 18(4): 526-539.

41. Ntoumanis N, Biddle SJH, Haddoc G (1999) The mediating role of coping strategies on the relationship between achievement moti- vation and affect in sport. Anxiety, Stress and Coping 12(3): 299-327.

42. Pensgaard AM, Roberts GC (2003) Achievement goal orientations and the use of coping strategies among winter Olympians. Psychology of Sport and Exercise 4: 101-116.

43. Giacobbi PR, Weinberg RS (2000) An examination of coping in sport: individual trait anxiety differences and situational consistency. The Sport Psychologist 14(1): 42-62. 
44. Stober J (2004) Dimensions of test anxiety relations to ways of coping with pre-exam anxiety and uncertainty. Anxiety, Stress, and Coping 17(3): 213-226.

45. Williams JM, Krane V (1992) Coping styles and self-reported measures of state anxiety and self-confidence. Journal of Applied Sport Psychology 4(2): 134-143.

46. Gaudreau P, Blondin JP (2004a) Different athletes cope differently during a sport competition: A cluster analysis of coping. Personality and Individual Differences 36: 1865-1877.

ISSN: 2574-1241

DOI: 10.26717/BJSTR.2020.26.004354

Hafeez ul Haq. Biomed J Sci \& Tech Res

(c) (i) This work is licensed under Creative

Submission Link: https://biomedres.us/submit-manuscript.php
47. Gaudreau P, Nicholls A, Levy AR (2010) The Ups and Downs of Coping and Sport Achievement: An Episodic Process of Analysis within Person Associations. Journal of Sport \& Exercise Psycho 298-311.

48. Nicholls AR, Polman R, Levy AR (2010) Coping self-efficacy, precompetitive anxiety, and subjective performance among athletes. European Journal of Sport Science 10: 97-102.

49. Nicolas M, Gaudreau P, Franche V (2011) Perception of coaching behaviors, coping, and achievement in a sport competition. Journal of Sport and Exercise Psychology 33(3): 460-468.

\begin{tabular}{ll} 
BIOMEDICAL & Assets of Publishing with us \\
RESEARCHES & - Global archiving of articles \\
\hline ISSN: $2574-1241$ & - Immediate, unrestricted online access \\
&
\end{tabular}

